\title{
KECANDUAN GADGET PADA SISWA KELAS XI DI SMK NEGERI 1 LAHAT
}

\author{
Teresya Bella Dwi Prizki ${ }^{1}$, Syska Purnama Sari ${ }^{2}$ \\ Universitas PGRI Palembang ${ }^{1}$ \\ Email: teresyabella82@gmail.com \\ Universitas PGRI Palembang ${ }^{3}$ \\ Email: syskapurnamasri@ gmail.com
}

\begin{abstract}
ABSTRAK
Penelitian ini dilatarbelakangi dengan ditemukannya di sekolah banyaknya siswa yang membawa handphone kesekolah. Bermain game, tiktok, membuka instagram bahkan siswa tidak fokus belajar karena sambil memainkan handphone pada saat proses pembelajaran berlangsung. Penelitian ini bertujuan untuk mengetahui seberapa besar persentase gambaran kecanduan gadget pada siswa. Penelitian ini menggunkan metode deskriptif kuantitatif. Menggunakan google form dengan membagikan link angket kepada siswa, sampel penelitian ini berjumlah 30 siswa kelas XI di SMK Negeri 1 Lahat yang di ambil dengan teknik purposive sampling. Teknik pengumpulan data berupa angket Kecanduan gadget dengan uji validitas 3,61 menggunakan korelasi product moment dan realiabilitas menggunakan rumus alpha cronbach. Hasil dari penelitian ini menunjukkan bahwa kecanduan gadget pada siswa kelas XI di SMK Negeri 1 Lahat berada pada kategori Tinggi 56,66\% kategori Sedang 23,33\% kategori Rendah 16,66\% Sangat Rendah 3,33\% dan tidak ada yang beradah pada kategori Sangat Tinggi. Berdasarkan data di atas maka rata-rata kecanduan gadget pada siswa kelas XI di SMK Negeri 1 Lahat berada pada kategori Tinggi sehingga diharapkan bisa menjadi acuhan untuk guru bimbingan dan konseling berperan aktif terhadap prestasi belajar peserta didik, senantiasa meningkatkan pengetahuan, keterampilan, kompetensinya dalam mengatasi berbagai permasalah di sekolah dan memberikan layanan bimbingan dan konseling di sekolah.
\end{abstract}

Kata kunci: Kecanduan Gadget, siswa.

\section{GADGET ADDICTION IN CLASS XI STUDENTS IN SMK NEGERI 1 LAHAT}

\section{ABSTRACT}

This research is motivated by the finding in schools that many students bring cellphones to school. Playing games, tiktok, opening Instagram, even students do not focus on learning because they play their cellphones during the learning process. This study aims to determine how much the percentage of the description of gadget addiction in students. This research uses descriptive quantitative method. Using google form by distributing questionnaire links to students, the sample of this study was 30 students of class XI at SMK Negeri 1 Lahat who were taken by purposive sampling technique. Data collection techniques in the form of a gadget addiction questionnaire with a validity test of 
3.61 using product moment correlation and reliability using the alpha cronbach formula. The results of this study indicate that gadget addiction in class XI students at SMK Negeri 1 Lahat is in the High category 56.66\% Medium category $23.33 \%$ Low category $16.66 \%$ Very Low $3.33 \%$ and no one is in the category Very high. Based on the data above, the average gadget addiction in class XI students at SMK Negeri 1 Lahat is in the High category so that it is hoped that it can become an indifference for guidance and counseling teachers to play an active role in student learning achievement, constantly improving knowledge, skills, and competence in coping. various problems at school and provide guidance and counseling services in schools.

\section{Keywords: Addiction Gadget, students}

\section{PENDAHULUAN}

Seiring dengan pengetahuan dan perkembangan zaman yang sangat mengalami kemajuan pada bidang informasi pada zaman sekarang, menjadikan tata cara kehidupan berubah. Salah satu contoh perkembangan tersebut yaitu alat komunikasi yang dapat menjadikan segala sesuatu menjadi mudah yaitu gadget.

Bagi masyarakat umum saja yang menggunakan gadget. Dikalangan pelajar yang masih duduk di bangku sekolah hamper semua sudah menggunakan gadget. masing-masing bisa dikatakan sudah hamper memiliki gadget. bagi pelajar gadget merupakan sarana untuk mencari tugas sekolah, mendapatkan teman di media social, dan bisa jadi untuk dijadikan sarana guna menyingkirkan kebosanan. Bagi siswa yang berada di sekolah gadget bukanlah sarana yang baru.

Menggunakan gadget bagi pelajar bukanlah hal yang baru tetapi sudah sangat mahir dalam memainkan gadget. kegiatan belajar mengajar dan pembelajaran yang termasuk kedalam belajar sendiri dengan adanya gadget semua siswa belajar dari menggunakan buku sekarang malah kebanyakan siswa beralih ke internet yang menggunakan gadget. Tetapi tidak semua pengguna gadget dimanfaatkan untuk belajar oleh siswa, penggunaan gadget sekarang banyak sekali yang menggunakannya hanya untuk hiburan saja dan melupakan kegiatan pembelajaran. Dizaman yang semakin canggih ini, semakin banyak sekali pelajar yang sangat tidak peduli dengan situasi sekitar dan terlalu focus pada gadget. Contohnya saja pada saat teman kita mengajak berbicara tidak ada respon sama sekali. di karenakan terlalu sibuk dengan gadget. Ini tentunya berdampak terhadap perkembangan sosialisasi anak. Pelajar menjadi orang yang tidak peduli dan menjadi orang yang cuek serta tidak mempunyai rasa peka terhadap orang lain. 
Hasil penelitian Diniati (2017) yang berjudul "Layanan Bimbingan Kelompok Dalam Mengurangi Kecanduan Anak Yang Menggunakan Gadget di Smk Negeri 1 Paringin" sempel penelitian ini adalah 10 orang siswa yang merasa kecanduan gadget, baik dirumah maupun di SMK Negeri 1 Paringin. Metode pengumpulan data penelitian menggunakan wawancara, observasi, dan dokumentasi. Teknik analisis data dalam penelitian ini menggunakan tindakan kuantitatif dan analisis observasi. Hasil penelitian menggatakan bahwa pelaksanaan bimbingan kelompok dapat mengurangi kecanduan anak yang menggunakan gadget.

Kebiasaan menggunakan gadget berlama-lama dan berkontak mata di depan layar gadget, yang tentu saja akan berdampak pada kesehatan mata. Kedipan mata sangat penting untuk mengurangi resiko mata kering. Semakin lama mata terbuka, semakin tinggi kemungkinan kornea mata mengalami dehidrasi, merasa panas, sakit atau seperti ada pasir dikelopak mata hingga terasa berat, ketergantungan gadget dalam individu tersebut yang dapat merugikan kondisi tubuhnya seperti malas belajar, kurang gerak yang akan menyebabkan obesitas.

Terkait dengan penggunaan gadget, fenomena yang terjadi yaitu, di SMK Negeri 1 Lahat diperoleh informasi bahwa kecanduan gadget siswa pada kelas XI SMK Negeri 1 Lahat berada kategori tinggi. Hal ini dapat di lihat melalui kecanduannya. Hasil penelitian ini bersamaan dengan penelitian yang dilakukan oleh Judhita dalam (Anandio 2018:9), penggunaan gadget pada kategori tinggi yaitu penggunaan gadget lebih dari 3 jam dalam sehari. Mereka cenderung menggunakan gadget mengikuti trend saat ini. Dilanjutkan dengan informasi dari guru BK, bahwa siswa/i di sekolah SMK Negeri 1 Lahat, rata-rata siswa membawa handphone kesekolah. Bermain game, tiktok, membuka instagram bahkan siswa tidak fokus belajar karena sambil memainkan handphone pada saat proses pembelajaran berlangsung. Peneliti mewawancarai beberapa siswa disana bahwa mereka tidak bisa lepas/meninggalkan HP mereka dirumah karena sudah kecanduan pada gadget. Maka dari itu mereka perlu diberikan bimbingan oleh guru bimbingan dan konseling (BK) agar mereka dapat mengetahui gambaran kecanduan gadget agar mereka lebih bisa mengatur waktu dan lebih bijak lagi dalam menggunakan gadget dengan baik. 
Penelitian ini perlu di lakukan agar mengetahui gambaran kecanduan gadget pada siswa terhadap bimbingan dan konseling agar diharapkan siswa menggunakan gadget dengan baik dan bijak yang akan memberikan manfaat, begitu juga sebaliknya, apabila pelajar lebih mengutamakan gadget dibandingkan dengan belajar maka lebih banyak dampak negatif yang ditimbulkan. Karena sekarang ini dampak dari gadget sangat beragam bagi pelajar. Banyak pelajar yang lupa waktu serta tugas sekolah yang tidak dikerjakan, dikarenakan terlalu asyik untuk memainkan gadget. Hal ini tentu harus diperhatikan dengan bantuan guru bimbingan dan konseling disekolah tentang pengawasan penggunaan gadget. Berdasarkan dengan masalah tersebut peneliti tertarik untuk meneliti dengan mengangkat judul penelitian kecanduan gadget pada siswa kelas xi di SMK Negeri 1 Lahat. Adapun yang menjadi batasan masalah penelitian ini agar tidak meluas dan lebih memperjelas arah permasalahannya. Maka peneliti memfokuskan batasan masalahnya mengenai siswa yang membawa gadget kesekolah, bermain game, tiktok, membuka intagram bahkan siswa tidak fokus belajar karena sambil memainkan gadget pada saat proses pembelajaran berlangsung.

\section{METODE PENELITIAN}

Jenis penelitian ini menggunakan metode penelitian kuantitatif dengan metode deskriptif. Menurut Lehmann (Yusuf, 2005) penelitian deskriptif yaitu penelitian yang mendeskripsikan secara sistematis, aktual dan akurat mengenai fakta-fakta dan sifat populasi tertentu, atau mencoba menggambarkan fenomena secara detail. Dapat disimpulkan bahwa penelitian deskriptif kuantitatif yaitu data yang diperoleh dari sempel dan populasi dan dianalisis dengan metode yang digunakan.Teknik yang digunakan dalam pengambilan sampel pada penelitian ini adalah peneliti menggunakan teknik purposive sampling. Teknik pengambilan sampel menggunakan teknik purposive sampling, kriteria yang dimaksut adalah siswa yang sering kedapatan memainkan gadget, tiktok, game bahkan siswa yang tidak fokus belajar karena selalu memainkan gadget dikelas. Jadi sampel dalam penelitian ini adalah seluruh siswa kelas XI TKJ di SMK Negeri 1 Lahat yang berjumlah 30 siswa. 
Instrumen penelitian untuk mengukur kecanduan gadget pada siswa digunakan angket dengan skala likert. Sebelum disebarkan intrumen telah diuji cobakan, yaitu uji validitas dan uji reliabilitas sehingga diperoleh instrument dengan butir soal sebanyak 24 buah dan reliabel keseluruhan sebesar 0,906. Teknik analisis data yang digunakan adalah teknik persentase. Deskripsi Kecanduan gadget siswa berdasarkan norma kategori diklasifikasikan dengan kriteria sangat tinggi, tinggi, sedang, rendah, sangat rendah. Kategorisasi dilakukan untuk menempatkan individu ke dalam kelompok-kelompok yang terpisah secara berjenjang menurut suatu kontinum berdasar atribut yang diukur.

\section{HASIL DAN PEMBAHASAN PENELITIAN}

Data dalam penelitian ini berupa hasil angket kecanduan gadget pada siswa. Kemudian, analisis data yang digunakan dalam penelitian ini adalah teknik persentase. Data hasil kecanduan gadget pada siswa kelas X di SMK Negeri 1 Lahat dapat dilihat pada Lampiran 1. Adapun deskriptif statistik kecanduan gadget pada siswa kelas $\mathrm{X}$ di SMK Negeri 1 Lahat didapat skor terendah (minimum) 30, skor tertinggi (maksimum) 95, rerata (mean) 72, nilai tengah (median) 84,91, nilai yang sering muncul (mode) 84,7, standar deviasi (SD) 11,83 .

\section{Deskriptif Statistik Tingkat Kecanduan Gadget siswa}

\begin{tabular}{|c|c|}
\hline \multicolumn{2}{|c|}{ Statistik } \\
\hline$N$ & 30 \\
\hline Mean & 72 \\
\hline Median & 84,91 \\
\hline Mode & 84,7 \\
\hline Std, Deviation & 11,83 \\
\hline Minimum & 30 \\
\hline Maximum & 95 \\
\hline
\end{tabular}

Apabila ditampilkan dalam bentuk distribusi frekuensi hasil angket kecanduan gadget pada siswa kelas XI di SMK Negeri 1 Lahat tabel 12 sebagai berikut:

Tabel 12 Distribusi Frekuensi Kecanduan Gadget Siswa

\begin{tabular}{|c|c|c|c|c|}
\hline No & Interval & Kategori & Frekuensi & Persentase (\%) \\
\hline 1 & 97 s.d 120 & Sangat Tinggi (ST) & 0 & 0 \\
\hline 2 & 78,91 s.d 96 & Tinggi (T) & 17 & 56,66 \\
\hline
\end{tabular}




\begin{tabular}{|c|c|c|c|c|}
3 & 67,09 s.d 77,91 & Sedang (S) & 7 & 23,33 \\
\hline 4 & 49 s.d 66,09 & Rendah (R) & 5 & 16,66 \\
\hline 5 & $\leq 48 \quad$ & Sangat Rendah (SR) & 1 & 3,33 \\
\hline \multicolumn{2}{|c|}{ Jumlah } & $\mathbf{3 0}$ & $\mathbf{1 0 0}$ \\
\hline
\end{tabular}

Berdasarkan distribusi frekuensi pada tabel 12 tersebut di atas, kecanduan gadget pada siswa kelas X di SMK Negeri 1 Lahat dapat disajikan pada histogram berikut:

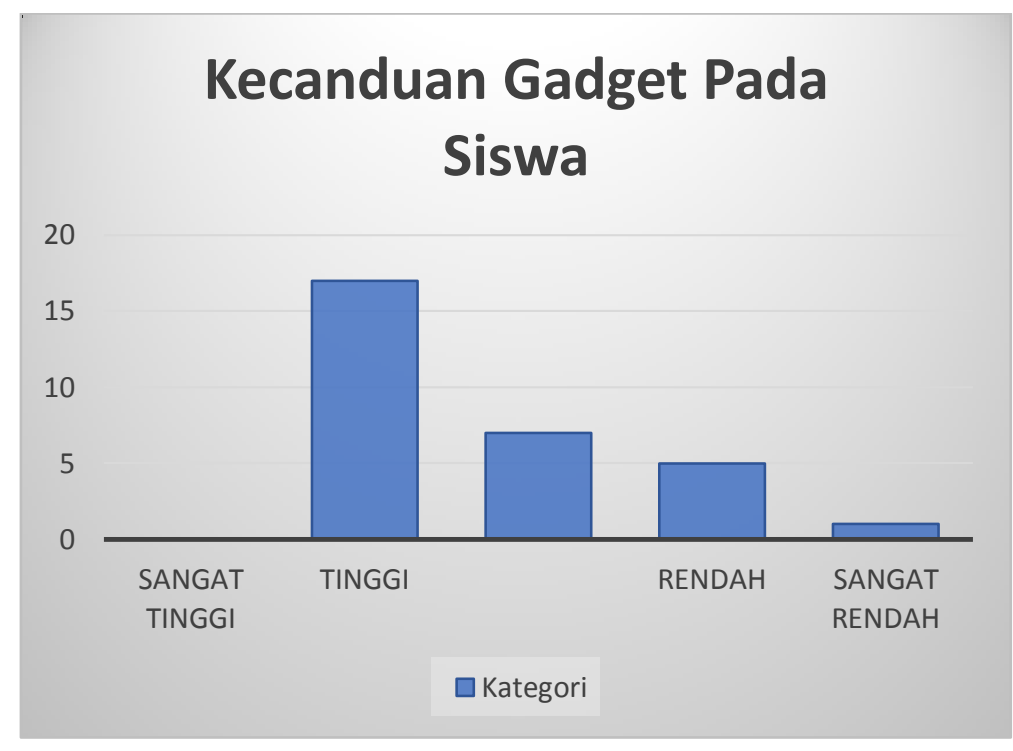

\section{Gambar 1. Histogram Kecanduan gadget pada siswa kelas XI di SMK Negeri}

\section{Lahat}

Berdasarkan tabel 12 dan gambar 1 terlihat bahwa dari jumlah keseluruhan sampel yang berjumlah 30 siswa, sebagian besar Kecanduan gadget mereka berada pada kategori tinggi dengan jumlah frekuensi 17 dengan nilai 56,66\% artinya siswa tidak mampu mengendalikan diri dalam bermain gadget, memiliki obsesi yang tinggi dalam bermain gadget, tidak mampu mengontrol waktu dalam bermain gadget, memberi pengaruh negatif pada diri siswa dan siswa selalu berfokus pada gadget yang dimilikinya. Selanjutnya dengan kategori sedang dengan frekuensi 7 dengan nilai $23,33 \%$ artinya siswa cukup mampu mengendalikan diri dalam bermain gadget, cukup baik dan tidak memiliki obsesi yang tinggi dalam bermain gadget, cukup mampu mengontrol waktu bermain gadget, tidak memberi pengaruh negatif pada diri siswa dan siswa tidak selalu berfokus pada gadget yang dimilikinya. Selanjutnya dengan kategori rendah 
dengan frekuensi 5 dengan nilai $16,66 \%$, artinya siswa mampu mengendalikan diri dalam bermain gadget, siswa lebih baik dan tidak memiliki obsesi yang tinggi dalam bermain gadget, mampu mengontrol waktu bermain gadget, tidak memberi pengaruh negatif pada diri siswa dan siswa tidak selalu berfokus pada gadget yang dimilikinya. kemudian kategori sangat rendah dengan frekuensi 1 dengan nilai $3,33 \%$ yang artinya siswa sangat mampu mengendalikan diri dalam bermain gadget, tidak memiliki obsesi yang tinggi dalam bermain gadget, sangat mampu mengontrol waktu bermain gadget, tidak memberi pengaruh negatif pada diri siswa dan siswa tidak selalu berfokus pada gadget yang dimilikinya. dan selanjutnya kategori sangat tinggi tidak ada yang beradah pada kategori Tinggi. Artinya siswa sangat tidak mampu mengendalikan diri dalam bermain gadget, sangat memiliki obsesi yang tinggi dalam bermain gadget, sangat tidak mampu mengontrol waktu bermain gadget, sangat memberi pengaruh negatif pada diri siswa dan siswa selalu berfokus pada gadget yang dimilikinya.

Berdasarkan data yang didapat dengan hasil instrumen yang terdiri dari 30 butir item pernyataan yang diberikan kepada 30 responden, kemudian dianalisis dengan teknik statistik dan menggunakan rumus persentase untuk mendapatkan gambaran variabel kecanduan gadget pada siswa. Maka persentase yang didapat yaitu $56,66 \%$. yang dikategorikan tinggi (T) bahwa siswa masih perlu bimbingan dalam mengatur aspek kecanduan Gadget agar lebih mampu membedakan waktu bermain gadget, agar tidak memiliki obsesi yang tinggi dalam bermain gadget, agar mampu mengontrol waktu bermain gadget, agar tidak memberi pengaruh negatif pada diri siswa dan siswa tidak selalu berfokus pada gadget yang dimilikinya. kategori Sedang (S) dengan persentase yang didapat 23,33\% selanjutnya kategori Rendah (R) dengan persentase yang didapat 16,66 selanjutnya kategori Sangat Rendah (SR) dengan persentase yang didapat 3,33 Sedangkan Kecanduan gadget siswa pada kategori Sangat tinggi tidak ada siswa yang berada pada kotegori sangat tinggi (ST). 


\section{PEMBAHASAN}

Berdasarkan data di atas maka Kecanduan gadget siswa kelas XI di SMK Negeri 1 Lahat berada pada kategori Tinggi. Hasil penelitian menunjukan persentase yang paling tinggi pada kategori Tinggi (T) yaitu sebesar 56,66\%. Menurut Shirinkam, dkk (2016) menyatakan bahwa skor kecanduan gadget yang tinggi dapat menyebabkan gangguan fungsi konteks otak yang dapat menghambat kognitif dan mekanisme kontrol korteks otak, sehingga kontrol diri yang tinggi memiliki potensi untuk mengurangi terjadinya kecanduan gadget pada individu. Menurut Anandio, dkk (2018) Penggunaan gadget bagi pelajar sebagai sarana untuk mencari tugas sekolah dan mencari teman di media sosial, atau bahkan untuk menghilangkan kebosanan. Gadget bukanlah hal baru lagi bagi pelajar yang ada di sekolah. Para pelajar masa kini sudah mahir dalam menggunakan gadget.

Menurut Manumpil dalam Anandio (2018), mengatakan bahwa siswa yang menggunakan gadget pada kategori tinggi yaitu 11 jam dalam sehari dan gadget digunakan untuk browsing materi pembelajaran. Bahkan paling banyak digunakan untuk bermain game online serta untuk mengakses berbagai media sosial yang ada seperti, intagram, path, facebook, dan twitter. Mereka sangat cenderung mengikuti trend saat ini dalam menggunakan gadget.

Maka dari itu guru bimbingan dan konseling bisa memberikan layanan BK sebagai srategi untuk mengurangi kecanduan gadget pada siswa. Salah satunya layanan bimbingan kelompok, layanan informasi, konseling individu. Menurut Mu'awanah dan Hidayah (2009) bimbingan kelompok merupakan sebuah kegiatan bimbingan yang dikelola secara klasikal dengan memanfaatkan satuan/grup yang dibentuk untuk keperluan administrasi dan peningkatan interaksi siswa dari berbagai tingkatan kelas. Sedangkan menurut Yusuf (2006) bimbingan kelompok yaitu pemberian bantuan kepada siswa melalui situasi kelompok. Masalah yang dibahas dalam bimbingan kelompok adalah masalah yang dialami bersama dan tidak rahasia, baik menyangkut masalah pribadi, sosial, belajar, maupun karir.

Menurut Winkel (2012) layanan informasi adalah layanan bimbingan dan konseling yang memungkinkan siswa menerima dan memahami berbagai informasi seperti informasi pendidikan dan informasi jabatan yang dapat 
digunakan sebagai bahan pertimbangan dan pengambilan keputusan untuk kepentingan siswa.

Selanjutnya menurut Nurihsan (2010) juga mengemukakan bahwa layanan informasi adalah layanan yang memberikan sejumlah informasi kepada peserta didik agar mereka memiliki informasi yang memadai baik informasi tentang dirinya maupun informasi lingkungannya. Informasi yang diterima oleh siswa merupakan bantuan dalam membuat keputusan secara tepat.

Implikasi bimbingan dan konseling dalam penelitian ini adalah keberadaan konselor, sebagai pembimbing dituntut peran aktifnya terhadap perkembangan prestasi belajar peserta didik. Konselor akan senantiasa meningkatkan pengetahuan, keterampilan, dan kompetensinya dalam mengatasi berbagai permasalahan di sekolah. Dengan kata lain tuntutan akan keprofesionalan konselor semakin nyata baik dalam pelaksanaan tugas sehari-hari maupun dalam penggunaan layanan bimbingan konseling.

\section{KESIMPULAN}

Dari hasil analisis data, deskripsi, pengujian hasil penelitian, dan pembahasan, dapat di simpulkan bahwa : Kecanduan gadget pada siswa kelas XI di SMK Negeri 1 Lahat yang terdiri dari 30 siswa sebagian besar hasil dari presentase kecanduan gadget berada pada kategori Tinggi (T) dengan jumlah persentase 56,66\%. Kategori Sedang (S) dengan persentase 23,33\% kategori Rendah (R) 16,66 Sangat Rendah (SR) dengan jumlah persentase 3,33\%. dan tidak ada yang berada pada kategori Sangat Tinggi (ST).

Guru bimbingan dan konseling bisa memberikan layanan BK sebagai srategi untuk mengurangi kecanduan gadget pada siswa. Salah satunya layanan bimbingan kelompok, layanan informasi, konseling individu. Konselor yaitu sebagai pembimbing peran aktifnya terhadap perkembangan prestasi belajar peserta didik, senantiasa meningkatkan pengetahuan, keterampilan, dan kompetensinya dalam mengatasi berbagai permasalahan di sekolah khususnya yang memiliki pemahaman yang tinggi tentang kecanduan Gadget. 


\section{DAFTAR PUSTAKA}

Alrasheed Bisma Kharisma, A. M. (2018). Hubungan antara kecanduan gadget dengan kecerdasan emosi pada remaja di SMP. Sains Psikologi, Vol 7 no 2, November 2018 Hal 136-142.

Anandio, dkk (2018). Program Studi Bimbingan dan Konseling. Kecanduan Gadget dan Interaksi Sosial siswa di Smk Muhammadiyah 2 Pekanbaru, Jom FKIP Volume 52018.

Dianti Ana, J. F. (2017). Layanan Bimbingan Kelompok dalam mengurangi kecanduan anak yang menggunakan gadget di SMK Negeri 1 Paringin. Mahasiswa BK An-Nur : Berbeda, Bermakna, Mulia, Volume 3 Nomor 3 Tahun 2017.

Fithri M,A.S (2019). Hubungan antara kecanduan Gadget dengan prokrastinasi Akademik. TRIADIK, Vol.18, No.1, April 2019.

Hadi, P. (2016). Upaya Meningkatkan Percaya Diri Siswa Melalui Layanan Bimbingan Kelompok di Sma Negeri 1 Sungkai Utara Lampung Utara. Lentera Pendidikan LPPM UM METRO, Vol. 1, No.1, Juni 2016 Hal 104.

Prayitno, Amti (2015). Dasar-dasar Bimbingan dan Konseling. Jakarta: PT RINEKA CIPTA.

Sitompul, D. N. (2015). Pengaruh Penerapan Layanan Bimbingan Kelompok Teknik Role-Playing Terhadap Perilaku Solidaritas Siswa Dalam Menolong Teman di SMA N 1 Rantau Utara. Edu Tech, Vol.1, No.1 Maret 2015.

Yusuf, Nurihsan (2014). Landasan Bimbingan dan Konseling. Bandung: PT REMAJA ROSDAKARYA. 